\title{
The Production Method of High Pressure Hydraulic Cylinders
}

\author{
Bauyrzhan Aimukhanbetuly Aimukhanbet ${ }^{1}$, Vitaly Vasilyevich Povetkin ${ }^{1}$, Auezhan Turdalievich Turdaliev ${ }^{1}$, \\ Azamat Turysbekovich Alpeisov ${ }^{1}$, Manshuk Fazylovna Kerimzhanova ${ }^{1} \&$ Mukhtarbek Kalmurzayevich \\ Tatybayev $^{1}$ \\ ${ }^{1}$ Kazakh National Technical University after K.I. Satpayev, Republic of Kazakhstan \\ Correspondence: Bauyrzhan Aimukhanbetuly Aimukhanbet, Kazakh National Technical University after K.I. \\ Satpayev, Republic of Kazakhstan. E-mail: baur.06@mail.ru
}

\author{
Received: October 15, $2014 \quad$ Accepted: October 25, $2014 \quad$ Online Published: December 7, 2014 \\ doi:10.5539/mas.v9n2p30 \\ URL: http://dx.doi.org/10.5539/mas.v9n2p30
}

\begin{abstract}
This paper deals with the questions of design, calculation methods, work reliability and providing a longer service life of hydraulic high pressure cylinders, with the possibility of using of additional technological solutions. This paper considers a method of assembling of cylindrical connections through a heating of a female part. Using these methods it is possible to improve a durability of force fittings, reduce a tightness and stress-strain state of assembly units, reduce time and energy costs for an assembling.

Offered technological method is related to machine-building hydraulic drive and can be used in coal, machine-building and other industries, in particular in mechanized supports for coal and other minerals underground mining. The design-engineering support was developed to improve reliability, work efficiency and operating characteristics of power hydraulic cylinders.
\end{abstract}

Keywords: hydraulic cylinders, a stress-strain state, thermal fitting, mechanized support

\section{Introduction}

Technology improving and an intensification of work processes in machines leads to a complication of their working conditions. In connection with this,performance requirements of machine parts increase and it determines an actuality of objectives for quality research and a search for new ways of its improve. Reliability and service life of machine partsis to a large extent determined by the state of their surface layer, its carrying capacity, which is formed within finishing operations and parts production and is determined by amanufacturing technology. In a modern manufacturing, a function and technological support of parameters of detailssurfaces'state is not adequately justified, that leads either to an overestimation of requirements and increase of machines' costs or to their underestimation and reliability decrease. As a rule, a cause of parts'breakage during an operation is the processes, occurring namely in a surface layer: stress concentration, a development of micro-cracks, softening, wear, oxidation (Aimukhanbet, 2009).

The structure of modern machine industry production includes a large number of power hydraulic cylinders, which ensure trouble-free operation of hydraulic equipment.

A use of hydraulic equipment allows you to create advanced machine design, to reduce their dimensions, increase operational life and enlarge abilities of automation control (Koval, 1979).

Taking into a consideration the importance of this equipment, to ensure the works' safety, hydraulic cylinders meet strict specifications both in terms of quality of production and a reliability of exploitation (Nabatnikov, 2012).

\section{Methods}

Theoretical studiesare based on the fundamental ideas of machine-industry technology, the theory of elastic-plastic deformation and mathematical statistics. The study used the systematic analysis, the method of the mathematical modeling and the finite elements method for assessing of the impact of the production precision and design parameters of the hydraulic cylinder on the formation of its state of stress and the magnitude of the contact stresses. 


\section{Results}

1 There was developed a method of technological production of a cylinder with a consideration of a deformation of a cylinder under the pressure ofthe working fluid.

2. There was reduced a stress-strain state of the walls of the hydraulic cylinders and the reduction of metal consumption, thereby reducing the longitudinal deformation (bending deflection).

\section{Discussion}

One of the main problems of the machine industry at the present stage of development is to improve the operational reliability of different products, which is largely determined by the durability of compounds (Oborskiy et al, 2008). The widespread use for the assembly ofsuch compounds technological methods of forming by thermal heating of female parts have received. Using these methods can improve the durability of force fittings, to reduce tightness and stress-strain state of assembly units, to reduce time and energy costs for the assembly.

Loaded joints are fixed and inseparable. The relative immobility of parts is provided by the mating surfaces'adhesion, which is created by the elastic deformation forces of a material, which are proportional to tightness. The mating surfaces of the parts are most often cylindrical (Figure 1).

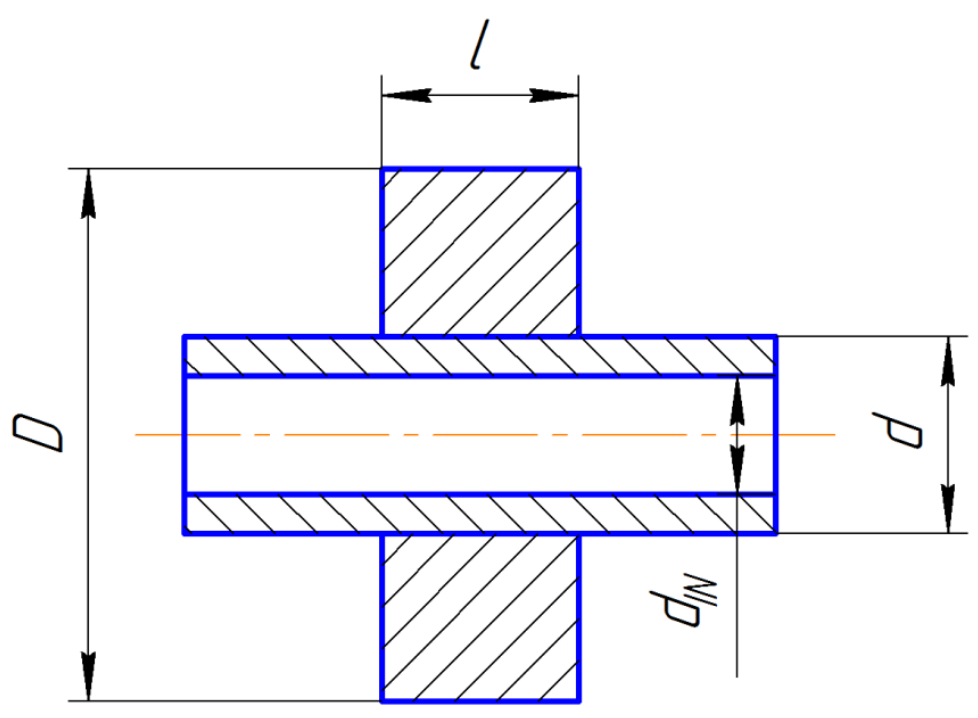

Figure 1. A cylindrical loaded joint

The internal surface of the cylinder and the outer surface of the rod andthe piston are working and their condition has a decisive influence on the work life of the joints. The main type of mechanized supports' failure is a violation of ahermiticity and hydraulic cylinders'leakage. In this case, the repair costs of hydraulic cylinders are over $60 \%$ of their initial cost.

The cylinder is deformed under the influence of the work fluid pressure, increasing in diameter. The magnitude of this deformation is comparable with gaps in joints, which could lead to a change of a rod position and to a change ofcontact surfaces'conditions. Depending on the magnitude of work fluid pressure the accumulation of the deformation of the cylinderoccurs, which increases the size of the clearance between the piston and the cylinder. This, in its turn, leads to an increase in normal stress contact areas. When contact stresses are higher than the critical level, details' working surfaces may be plastically deformed and collapsed.

More often,a hydraulic rack is directly deformed as well as bases and canopies of supports' sections. Therefore, much attention is paid to the cylinders of hydraulic racks by the improvement of the technological process.

The patent developments in the field of the hydraulic machine industry, in particular, production of hydraulic cylinders (Yuda, 1993; Owens, 1993; King, 2000; Miller, 2002; Franco, 2007; Salnikov, \&Vatulin, 1998; Lebedev, 1992; Bogdanov, 2001; Palevin, 2000; Novoselov, \& Lukyanov, 2011).The work is devoted to the development of technological solutions to improve the exploitation properties of cylinders of hydraulic racks of 
mechanized supports with the use of fine and hardening methods (Segal, 2006), in order to improve such exploitation characteristics as endurance, wear resistance, fatigue strength, corrosion resistance.

Through the use of thermal assembly process, in particular, with the heating of the female part,and the application of fine and hardening method, we receive a positive result with an increase in strength, endurance of the cylinders and reduction of their stress-strain state.

Formula: 1 A method for production of a high pressure hydraulic cylinder, is characterized by the fact that for (uniform distribution) reduction of the stress-strain state of the hydraulic cylinder walls and reduction of the metal consumption, thereby reduction of the longitudinal deformation (deflection), on the outer surface of the hydraulic cylinder 1 one or a number of technological rings (reinforcement rings) 2 are thermally pressed, allowing to reduce the longitudinal deformation (Figure 2).

2. The method according to the 1 point is characterized by the fact that the step of the pressed-on technological rings and their widths depend on the inside pressure of the hydraulic system and is in the proportions of 1:2, 1:4, $1: 8$, and so on to the last.

3. After the thermal fitting of the technological rings on the cylinder, the inner surface of the cylinder, wherein after the mechanical treatment the oversize was left, is treated with fine and hardening method, i.e. the rolling by rollers.

For this method of hydraulic cylinders' production an application for a preliminary patent in the Republic of Kazakhstan was sent.

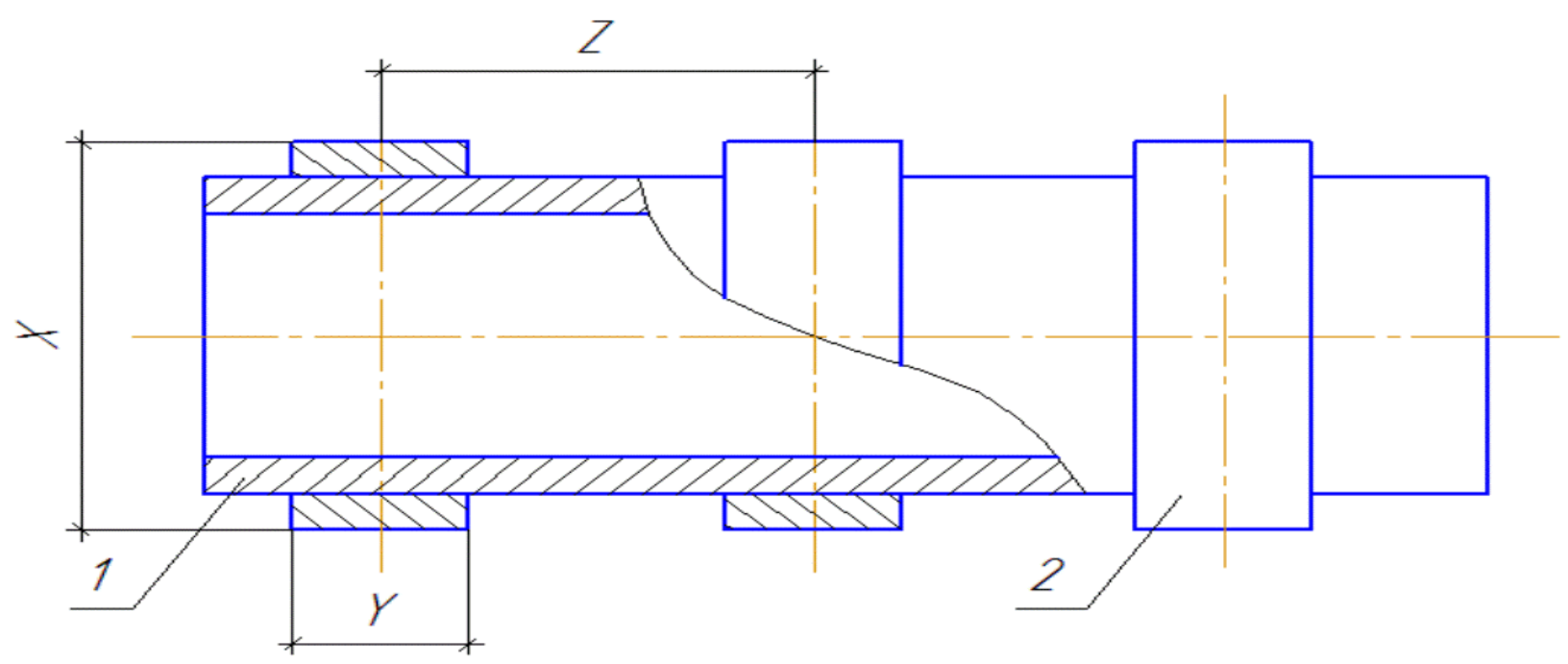

Figure 2. The method of hydraulic cylinders' production

The strength of a connection depends on the ability to resist the relative displacement of parts under the influence of an external axial force $P$ (shift) (Figure 3) and rotation torque $T_{r}$ (turn). Terms of strength are expressed by the inequalities:

$$
\begin{gathered}
P \leq \pi d l p(f-\operatorname{tg} \alpha) \\
T_{r} \leq 0.5 \pi d^{2} l p f
\end{gathered}
$$

where $d$-a nominal diameter; $l$ - a contactlength of mating surfaces; $p$ - an average pressure on contacting surfaces; $f$-coefficient of cohesion with an axial shear and torsion; $\alpha$ - aninclinationangle of a cone; for cylindrical joints $\alpha=0$.

Within practical calculations of steel parts' joints the adhesion coefficient was assumed as equal during the heated assembly of the female part $f=0.14$ (Grechishchev and Iliashenko, 1981). 


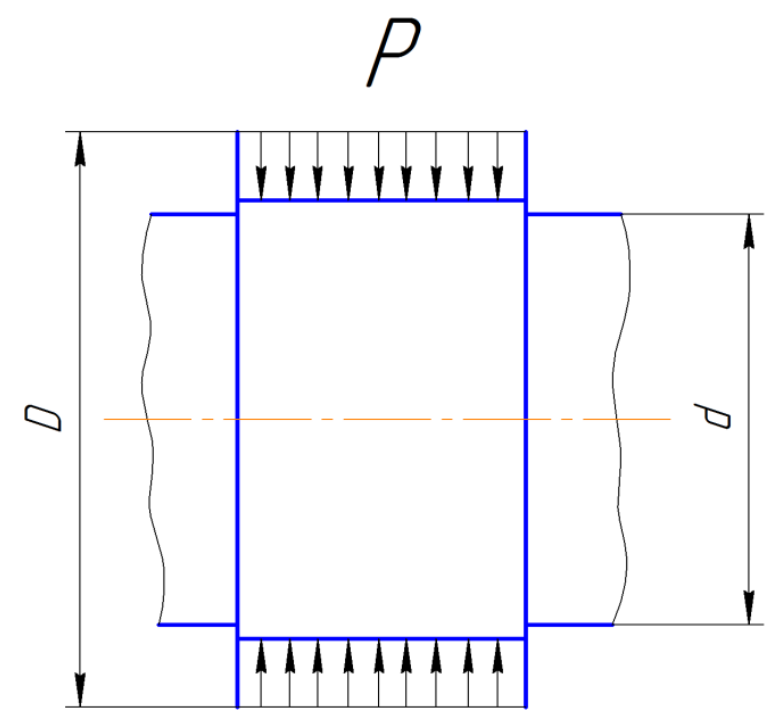

Figure 3. The cylindrical joint with the loading by the axial force $P$

The required specific pressure $\mathrm{p}$ on the mounting surface of the cylindrical force fitting joint is determined by the following formula:

$$
p=\frac{1}{d} \frac{N_{r}}{\left(\frac{C_{1}}{E_{1}}+\frac{C_{2}}{E_{2}}\right)}
$$

Here $N_{r}-$ arated preload; $E_{l}$ and $E_{2}-$ modules of materials'elasticity, respectively male (1) and female (2) parts; $C_{1}$ and $C_{2}$ are dimensionless coefficients:

$$
C_{1}=\frac{d^{2}+d_{0}^{2}}{d^{2}-d_{0}^{2}}-\mu_{1}, C_{2}=\frac{D^{2}+d^{2}}{D^{2}-d^{2}}+\mu_{2}
$$

where $d_{0}-$ a hole diameter of a hollow shaft: with a solid shaft $d_{0}=0$ and $C_{1}=1-\mu_{1} ; \mu_{1}, \mu_{2}-$ Poisson's coefficients for the same materials; $D$-a diameter of an outer surface of a sleeve. The rated preload of the cylindrical joint $N_{r}$ is calculated by the formula

$$
N_{r}=p d\left(\frac{c_{1}}{E_{1}}+\frac{c_{2}}{E_{2}}\right)
$$

Where $p-$ a specific pressure, which is determined by the formula

$$
p=\frac{P}{\pi d l(f-\operatorname{tg} \alpha)}
$$

Measured preload $N_{m}$, which will provide a specified accuracy of ajoint must be greater than the calculated $N_{r}$ by the amount, which is equal to bradding ofmicroroughnesses' tips:

$$
N_{m}=N_{r}+1,2\left(R_{Z 1}+R_{Z 2}\right)
$$

Where $R_{Z 1}$ and $R_{Z 2}$ - themicroroughnesses' heights on the mated surfaces of the shaft and sleeve, respectively.

The height of the roughnesses $R_{Z 1}$ and $R_{Z 2}$ of the mated surfaces of the parts (Figure 4 ) are accepted depending on the adopted roughness classes of these surfaces (Gouzenko, 1964; Zenkin \& Arpentev, 1987). 

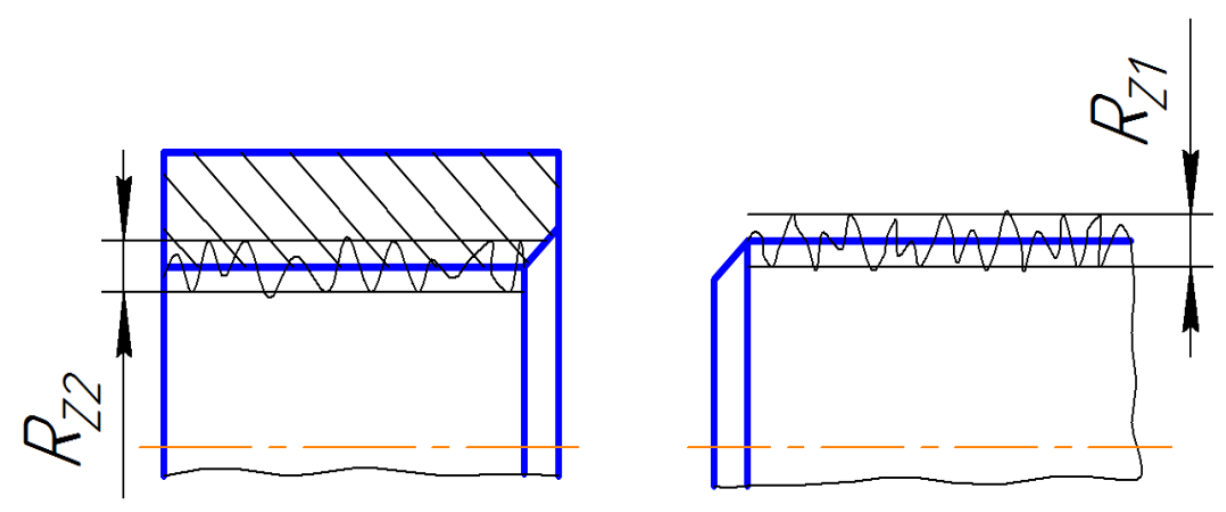

Figure 4. Theheightsofthe $R_{Z 1}$ И $R_{Z 2}$ roughnessesof the mated parts of the connected details

The resultant voltage $\sigma_{\text {R.I. }}\left(\mathrm{kgf} / \mathrm{cm}^{2}\right)$ on inner surfaces of walls in cylinders and rods of hydraulic racks is determined by the formula:

$$
\sigma_{R . I .}=\sqrt{\frac{1}{2}\left[\left(\sigma_{z}-\sigma_{r}\right)^{2}+\left(\sigma_{t}-\sigma_{r}\right)^{2}+\left(\sigma_{r}-\sigma_{z}\right)^{2}\right]}
$$

Where $\sigma_{\mathrm{z}}, \sigma_{\mathrm{t}}$ and $\sigma_{\mathrm{r}}$ - the constituents of the tension from the outer loads and the inner pressure of the work fluid (Aimukhanbet and Povetkin, 2014).

If the hub has a higher coefficient of linear expansion and the joint works at high temperatures, an amendment to reduce the preload $\Delta N$ is introduced:

$$
\Delta N=\left(K_{\alpha 2}-K_{\alpha 1}\right) d \Delta T
$$

where $K_{\alpha 1}$ and $K_{\alpha 2}$ - coefficients of linear expansion of a material, respectively, shaft and bushing; $\Delta T-$ excess of the operating temperature above the ambient temperature.

Plastic deformation in some mating areas, caused by uneven pressure due to the discreteness of the contact does not have a significant impact on the $p$ value. If aplastic deformation isconsiderable, strength calculations are conducted byspecified relations.

Dimensions of parts of joints after acylindrical jointassembly changewhile heating: an internal diameter of a male part is reduced at $U_{1}$, an outer diameter of a female part is increased by $U_{2}$, and a thickness of a female member $S$ is decreased by $\Delta S$.

$$
\begin{gathered}
U_{1}=\frac{2 p d^{2} d_{0}}{E_{1}\left(d^{2}-d_{0}^{2}\right)} \\
U_{2}=\frac{2 p d^{2} d_{2}}{E_{2}\left(D^{2}-d^{2}\right)} \\
\Delta S=\frac{2 \mu_{2} p S d}{E_{2}\left(D^{2}-d^{2}\right)}
\end{gathered}
$$

These dimensional changes must be considered. For high accuracy joints a final treatment of corresponding surfaces after assemblyshould be done.

Thermal assembly (heating of male or female parts) is provided by the creation of a gap between parts to be jointed. Details'assambly occurs due to changes in their size with changes in ambient temperature. A durability of such joints is as 1.5...2.5 times as more than those, which are received by press fit, due to mutual penetration ofmicroroughness.

Thermal assembly is used for mission-critical and large joints. The temperature should be as low as possible to reduce energy consumption. The average temperature to which the detail must be heated and cooled:

$$
T=\frac{N+i+\Delta d}{K_{\alpha} d} \pm T_{0}
$$


where $N$ - a joint preload; $i$-a thermal gap; $\Delta d$-adiametr change of mounting surface of a shaft and a hub due to temperature changes during transportation and basing; $K_{\alpha}-$ a coefficient of linear expansion of a material; $T_{0}-$ an ambient temperature, which was accepted with the "+" when heated and with the "-_"when cooled.

The temperature is controlled by a thermoelectric thermometers. The rate of heating or cooling is confined by the acceptedthermal stresses and deformations of its material.

To speed up an adhesion, assembled joint is heated (or cooled) by an air flow. A thermal assembly may be used with asprayed corrosion liquid.

A check calculation of parts is conducted by the formulas:

a) of a female part:

tension test

$$
\sigma_{t}=p_{\max } \frac{1+\left(\frac{d}{d_{2}}\right)^{2}}{1-\left(\frac{d}{d_{2}}\right)^{2}} \leq\left[\sigma_{t}\right]
$$

Shear test

$$
\tau_{s}=\frac{p_{\max }}{1-\left(\frac{d}{d_{2}}\right)^{2}} \leq\left[\tau_{s}\right]
$$

b) a male part compression test:

$$
\sigma_{C}=p_{\max } \leq\left[\sigma_{C}\right]
$$

Where values of the accepted stresses $\left[\sigma_{t}\right],\left[\tau_{s}\right] \mathrm{u}\left[\sigma_{c}\right]$ are accepted according to a material and a function of joint details, $p_{\max }$ - amaximum possible specific pressure of a joint, is determined by the following formula:

$$
p_{\max }=\frac{1}{d} \frac{N_{\max . r}}{\left(\frac{C_{1}}{E_{1}}+\frac{C_{2}}{E_{2}}\right)}
$$

where $N_{\text {max.r }}$ - maximum rated preload of a joint is determined by the formula:

$$
N_{\max . r}=N_{\max }-1,2\left(R_{Z 1}+R_{Z 2}\right)
$$

where $N_{\max }$ - maximum preload of a joint.

To select a type of aheat exposure it is required to be guided by the rule that it is better to cool and heat the leastmetal-intensive detail and at the same time to take into account its technological effectivness.

It should be noted that within a thermal assembly of cylindrical joints itis very important to know what may be a distribution of a temperature in mating parts at the time of an initial contact. This would allow determining a heating temperature more accurately within a development of a technology as well as afitting diameter increaseof a male and female parts, a size of a temporary assembly gap and costs of technological operations of anassembly cycle. 


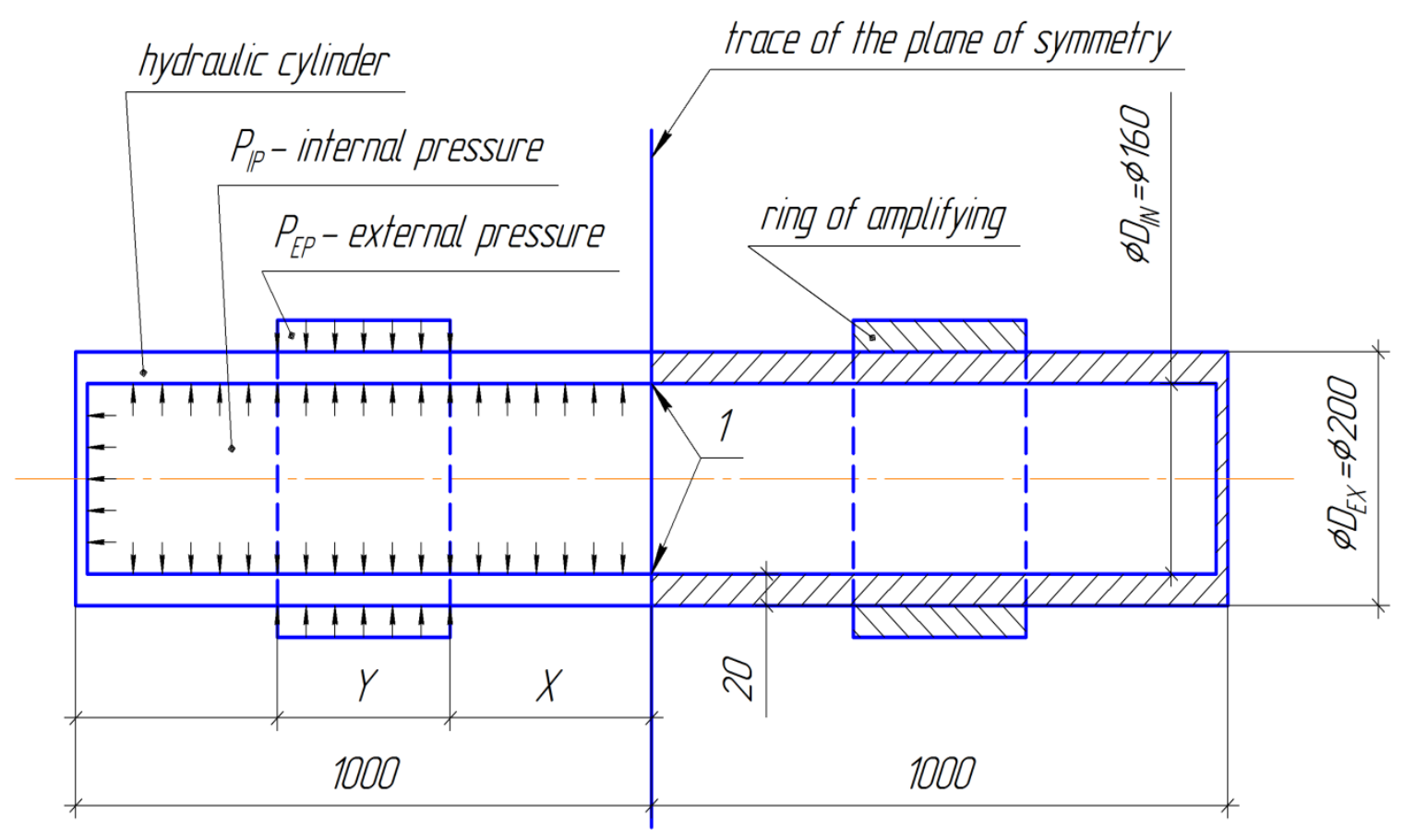

Figure 5. A schematic diagram for calculations

Figure 5 shows a schematic diagram for further calculations with different specified parameters. Calculations are conducted with different parameters'data of an internal and external pressure, parametersof internal and external diameters at various parameters ofastiffener ring. The recommended method of a cylinder (sleeve)production is to develop an optimal and cost-effective technological process for the production.

A cylinder (sleeve) is one of the most work intensive parts of a hydraulic cylinder, a quality of which influence largelyreliability and durability of the entire cylinder.

The technological process for the production of the cylinder sleeve is to use of the thermal fitting of the technological rings (stiffener rings) and the application ofthe finishing hardening method of the inner surface (diameter) treatment at the final stage, to be more exact, the method of surface plastic deformation.

This finishing and hardening method is economically feasible within the production of the hydraulic cylinders' sleeves, which are subjected to the very strict technical requirements of production.

The combination of a high surface roughness with a metal layersurface hardening (which not always takes place afterthe finishing cutting treatment) provides good exploitation properties of the parts, treated by plastic deformation: the surface hardness of the metal layer isimproved, the surface layer strength, yield stress, and in particular, the fatigue limit.

During aplastic deformation, atreated surface of even such soft ductile metals as copper and aluminum, remains clean, non-polluted, unlike an abrasive machining, which allows fragments of abrasive grains penetrating into a metal.

A treatment by a plastic deformation is much more saving than a cutting treatment, which is determined by the following factors:

a) ahigher productivity;

b) an ability to use more low-skilled workers;

c) a low cost of an instrument, made of carbon and alloy steels that do not contain such an expensive and scarce materials such as tungsten, titanium and cobalt, containing in large quantities in tool materials, used in the processing of the cutting tool.

The high stability of the tool during the plastic deformation treatment and stability of the state of their working surfaces in time (unlike the cutting and abrasive tools, whose working surface condition during operation varies continuously) creates the prerequisites for the automatization of thepressure treatmentmethods. 
All these advantages suggest machine parts and appliances finishingmethods of plastic deformation is very promising.

However, despite the advantages and great abilities, the plastic deformation treatment, as a finishing process, is still not widely used in industry, partly due to the almost complete lack of appropriate equipment in plants, as well as an insufficient study of this treatment method.

The metals'plastic deformation treatment is a kind of a pressure treatment, in which, with the help of various tools for working bodies a materialsurface layer of a machined detail isplastically deformed; it is applicable to recovery parts made of steel, cast iron, non-ferrous metals and alloys, whichare of sufficient plasticity (Balter, 1956).

Surface plastic deformation is a pressure materials' treatment (without a cutting), at which only a surface layer of apart is deformed.

The plastic deformation treatment, with an axial movement of the deforming rollers, theplastic deformation begins before rollers at some distance from the surface.

In the contact zone of the deforming rollers and the treated surface theretarded (pinched) wedge-shaped volume of the metal is formed, whichfacilitates the directed surface plastic deformation.

Metal is mainly moved in the circumferential direction. Inside the projections of themicroroughnesses anaxial flow of the metal is observed. The tops of the microroughnesses are plastically deformed, and there is a closure of cavities. The levelof the cavities location is kept practically constant.

The treatment, based on the plastic deformation of the surface layer has a number of advantages, compared to the treatment by turning, grinding, polishing, lapping, including:

- the integrity ofmetal fibers is kept and it forms a fine texture structure in a surface layer;

- noimpregnation of treated surface by particles of grinding wheels, polishing pastes;

- there are no thermal effects;

- treatment processes arestable andensure consistent quality of a surface;

- there is a possibility to achieve the minimum parameter of the surface roughness ( $\mathrm{Ra}=0.16 \ldots 0.32 \mu \mathrm{m}$ or less) both for heat-treated steel, nonferrous metals, and the high-strength materials, keeping the original shape of blanks;

- it is possible to reduce the surface roughness by several times within one stroke;

- create a favorable form of micro-roughnesseses with a greater degree of a bearing surface;

- there is a possibility of the formation of regular amicrorelief with a given area of recesses for a detention of lubricants;

- favorable residual compressive stresses in the surface layer are formed;

- $\quad$ asurface hardnessis increased.

The hardening of surface plastic deformation methods leads to significant changes in a surface layer of a metal: microroughnesses are smoothed and the strength of a layer isincreasedwith the formation of residual stresses of compression in it. Compressive stresses have the most impact on an endurance improvement, they shift critical stresses in a region of higher values, as well as slow down a process ofbirth and development of microdamages, reduce a sensitivity of a surface to a localization of stresses near concentrators. The surface plastic deformation reducesa surface roughness, it is characterized by large radii of unevennesses. This surface helps to increase an endurance of details, as it reduces a stress concentration in cavities of microroughnesses. In addition, a profile of bearing surface issignificantly increased, which contributes to a rapid mating parts'running-inin movable joints and greater durability in fixed fittings.

The essence of the process of rolling out is that under the pressure of hardened rollers microroughnesses of a treated surface is plastically deformed, filling microprofile cavities.

The effectiveness of rolling out depends on a number of factors and their combinations; these factors include:

- properties of a treated metal;

- condition of a surface, exposed by rolling out (roughness, waviness, microhardness);

- design, geometry and method of installation of a roller; 
- a scheme of rolling out and a construction of a rolling out device;

- a rolling out regime (pressure, feed, speed and cooling).

Compressive residual stresses arising in the surface layer of parts in strengthening treatment, positive impact on the performance of the products (Aimukhanbet \& Povetkin, 2013).

Such high technical and economic indicators suggest a method of treating rolling of the rollers is very promising and recommend it for implementation in practice of the most diverse branches of engineering.

A brief description of the process for the manufacture of cylinder liner will look like this:

1) a blanking operation

2) a check operation (a grade of materialcompliance control)

3) a turning operation (pre-treatment)

4) a turning operation (pre-treatment of an inner diameter of a sleeve with an oversize for the rolling out of 0.03-0.06 mm)

5) a benching operation (deburring after machining)

6) a thermal (thermal fitting of stiffener rings on a sleeve)

$7)$ a turning operation (final sizes)

8) rolling out (hardening of a sleeve inner surface by rolling out)

9) a cleaning of parts

10) a final control

A common disadvantage of an abrasion treatment is an effect of an impregnation of foreign particles in atreated surface, especially within soft materials' treatment (low-carbon steel, copper, aluminum and its alloys) and unfavorable sanitary conditions for machinists.

As finishing treatment, instead of an abrasive treatment, themost promising is the use of a method of surface plastic deformation. During processing, there is an intensive smoothing of surface roughnesses of a blank and it is accompanied by a significant hardening of surface layers (microhardnessincrease, a creation of favorable compressive stresses). An impregnation of foreign and other abrasive particles in a surface of a partexcluded, there are no thermal damages, and it becomes possible to form a partially or completely regular microrelief (Oteniy I. N., et al., 2000; Smelyanskiy, 2002; Smolnikov, et al., 2001; Smolnikov, et al., 2002, Schneider, 1998).

However, the method of surface plastic deformation is not related to the dimension, but to the finishing and hardening treatment without ametal oversize removal. Therefore, to achieve a desired quality of a surface layer and, if necessary, a precise size of a part, it must preceded by one of the types of dimensional processing by cutting.

Figure 6 shows the comparative costs of different methods of machining and achieve roughness. 


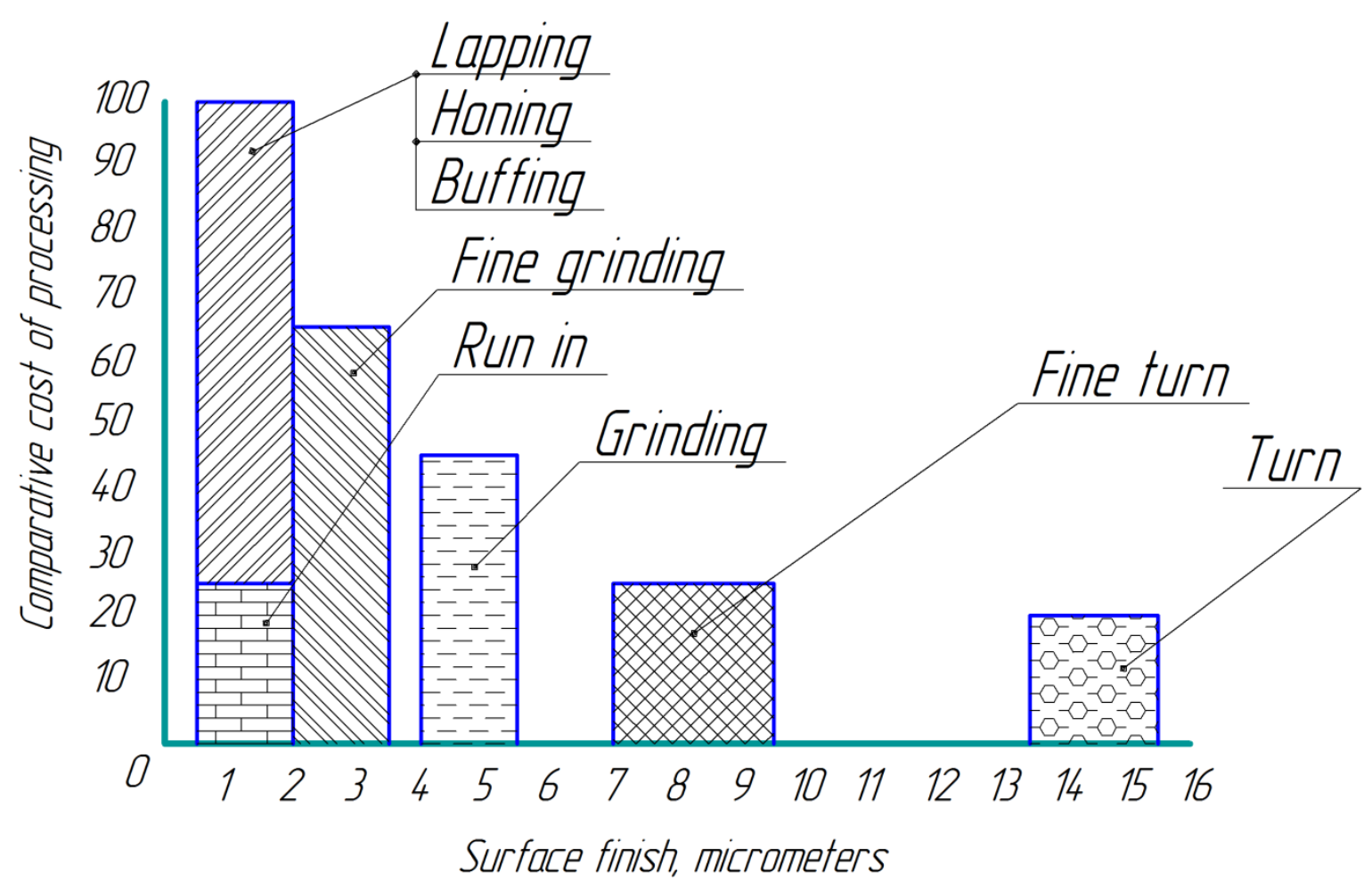

Figure 6. Comparative cost prices of different methods of finish treatment and obtained surface roughness

As it follows from the diagram, with anaccuracy increase and an achievement of a lower roughness a cost of atreatment increases sharply. The lowest cost corresponds to a treatment by rolling out and boring. At the same time thehigh efficiency is achieved and a roughness of the rolling out is comparable to a roughness, achieved during superfinishing.

Thus, the combined treatment method of cutting and surface plastic deformation of the rollers allows us to solve the issue of high efficiency with a given quality and low treatment self-cost. Within the combination of the cutting and plastic deformation treatment the total self-cost is $40 \%$ less in comparison with the finishing methods of theabrading treatment.

The rolling outof an inner surface of a cylinder will be made on arolling out device, which was developed by us on the basis of machine-building plant named after S.M. Kirov (Almaty, the Republic of Kazakhstan). A brief description of a device for rolling out is shown in Figure 7.

The rollers 1 are supported by a tapered mandrel 2 which, in its turn, is pressed into the sleeve 3 and is guided by the cage 4. A location of rollers on a conical mandrel leads to formation of the drop-shaped indentation on a treated surface, as within the finishingof outer surfaces. 


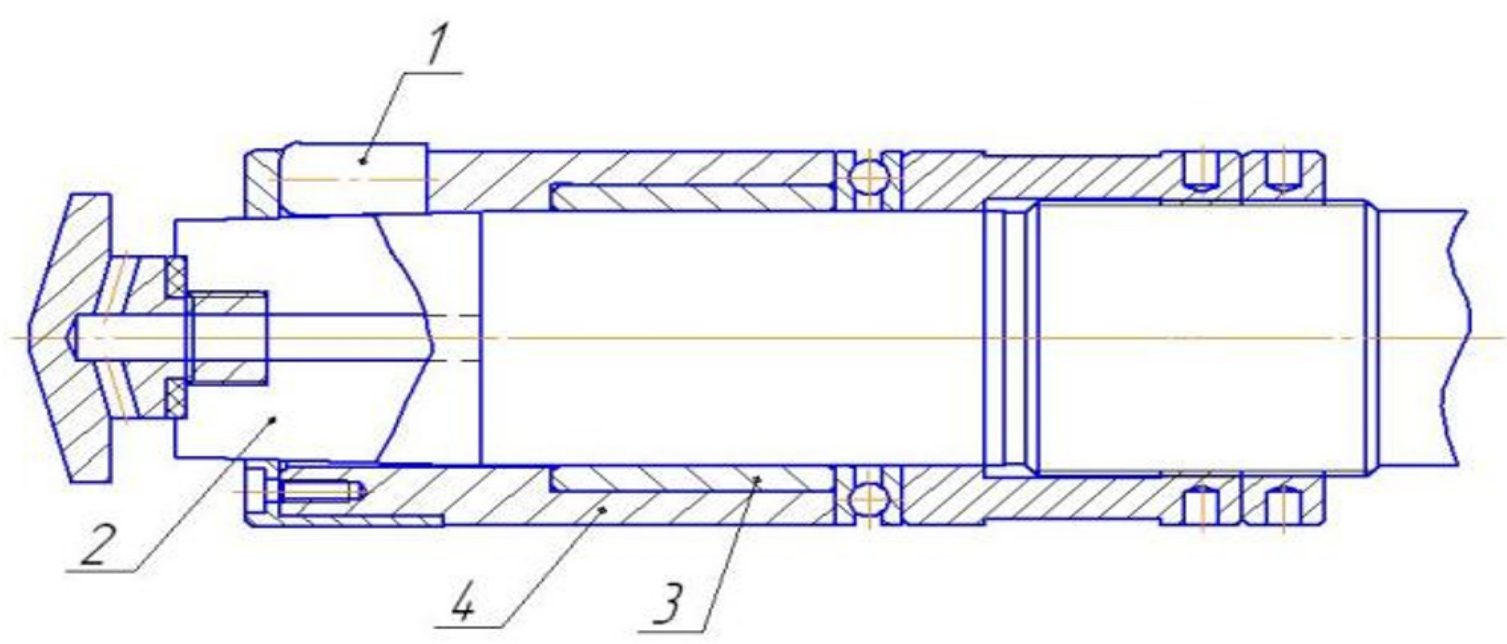

Figure 7. The device for the cylinder rolling out

The given rolling out allows obtaining surfaces of regular geometric shape, correcting deviations, obtained during pre-machining.

The offered method can be effectively used for a process of quality control for parts of a hydraulic cylinder to improve a quality (roughness class) and strength of a treated surface for final finishing and hardening treatment.

Rolling out is based on plastic properties of a metal and its ability to obtain permanent deformation without breakingunder the influence of external forces. Moreover, a surface layer is compacted, and its hardness and wear resistanceincreases. Rolling out allows obtaining a surface of regular geometric shape correcting deviations, obtained during preliminary machining, moreover, all the burrs from the cutting tool, obtained during boring, are rolled in to a roughness ofamirror surface. A roughness of a surface after the rolling out is Ra 0.16.

Rolling out is performed with one pass, moreover, rolling out heads are centered forcefully on the axis of the hole. Rolling out does not require special equipment and can be used on turning, drilling and boring machines. The inclination of the axis of the rollers relative to the rolling axis with $1^{\circ} 26^{\prime}$ provides anaxial movement of a rolling out tool through a treated surface without forced feeding. Rolling put is done under the following conditions: a speed of a running in tool over a surface of a cylinder sleeve $v=60 \div 70 \mathrm{~m} / \mathrm{min}$; feed $s=0.3 \div 0.5$ $\mathrm{mm} / \mathrm{rev}$; a pressure on one ball is $60-100 \mathrm{kgf}$.

\section{Conclusion}

To perform calculations to determine the optimum thickness of a wall of a hydraulic cylinder for a technological rings' fitting to obtain economic benefits and use of finishing and hardening treatment.

To perform calculations to determine a temperature of a fitting and parameters of fitted rings, and to determine a number of rings by calculating, depending on a length of a hydraulic cylinder.

\section{References}

Aimukhanbet, B. (2009). Design-engineering production support of the cylinder and rod type detail output.

Aimukhanbet, B., \& Povetkin, V. (2013). A modelling of a stress-deformed state of a surface layer within a method of a surface plastic deformation hardening. The digest of works of the $\mathrm{V}$ international scientific practical conference "The problems of innovational development of the oil and gas industry"-Kazakhstan-Britain Technical University, Almaty.

Aimukhanbet, B., \& Povetkin, V. (2014). The strength calculation of hydraulic cylinders of mechanized supports. The materials of theIII international scientific practicalconference"Fundamentalandapplied sciences today"Book 3, North Charleston, USA.

Balter, M. (1956). A detail surface hardening by roller burnishing. "The technology of the transport machine industry", VPTI, 2.

Bogdanov, A. (2001). Combined double acting hydraulic cylinder. Russia, \#2211967. 
Franco, P. (2007). Cylinder for pressurized fluids. Italy, \#EP 1772632A2.

Grechishev, E., \& Ilyashenko, A. (1981). Forced fittings: Calculations, engineering, production. Moscow: Machine industry.

Guzenkov, P. (1964). Short guidebook for machine details' calculations. Moscow: The high school.

King, J. (2000, September 5). Cylinder. United States Patent \#6, 112, 640.

Koval, P. (1979). Hydraulics and hydraulic drive of mining machine. Moscow: Nedra.

Lebedev, A. (1992). Power hydraulic cylinder. Russia, \#2037680.

Miller, G. (2002, August 27). Hydraulic and pneumatic cylinder construction. United States Patent \#6, 439, 103.

Nabatnikov, Y. (2012). The increase of the accuracy of the mechanized supports' power hydro cylinders' production. Moscow: Moscowstatemininguniversity.

Novoselov, B., \& Lukyanov, L. (2011). Hydraulic cylinder. Russia, \#2422685.

Oborskiy, I. L., et al. (2008). Theprovisionofqualityofloadedjoints, formedbythermalmethods. The materials of the $8^{\text {th }}$ international scientific-practical conference" Quality, standardization, control: theory and practice", Yalta city, Kiev, Ukraine.

Oteniy, Y., et al. (2000). The foundation of the optimal forms of the deforming rollers within the surface plastic deformation treatment method. The digest of the materials "The modern technologies in the machine industry". Part II. Penza.

Owens, C. (1993, January 21). Hydraulic cylinder with end closure assembly. United States Patent \#5, 487, 326.

Palevin, Y. (2000). Power hydraulic cylinder. Russia, \#2161253.

Salnikov, V., \& Vatulin, Y. (1998). The cylinder sleeve production method. Russia, \#2147518.

Segal, V. (2006). Metal processing by severe plastic deformation. Russian Metallurgy (Metally), 5, 474-483.

Shneider, Y. (1998). The pressure finish treatment technology: Guidebook. Saint Petersburg: Polytechnic.

Smelyanskiy, V. (2002). The mechanics of a detail hardening by a surface plastic deformation. Moscow: Machine industry.

Smolnikov, N., et al. (2001). The analysis of geometrical relations of a contact square between rollers and a detail within a surface plastic deformation. Promising technologies in the machine industry: The inter-universities digest of scientific worksUnder the edition of Orbinskiy V. M., VolgSTU, Volgograd, 4, 125-128.

Smolnikov, N., et al. (2002). The research of a contact zone on an experiment a lst and within the roller surfaces plastic deformation. Progressive technologies in education and manufacture: The materials of the Russian conference. Kamishin technological institute (branch), VolgSTU, Kamishin.

Yuda, L. (1993, September 21). Cylinderassemblyandmethod. United States Patent \#5, 245, 911.

Zenkin, A., \& Arpentyev, B. (1987). The fixed joints' assembly by thermal methods. Moscow: Machine industry.

\section{Copyrights}

Copyright for this article is retained by the author(s), with first publication rights granted to the journal.

This is an open-access article distributed under the terms and conditions of the Creative Commons Attribution license (http://creativecommons.org/licenses/by/3.0/). 